\section{Mães e vacinação das crianças: estudo de representações sociais em serviço público de saúde}

\section{Mothers and the vaccination of children: a study of social representations in the public health sector}

\section{Abstract}

Objectives: a survey of the factors involved in significant observance on the part of mothers of the National Immunization Program's vaccination calendar.

Methods: a study of 124 pregnants divided into two groups: 61 nulliparous pregnant women and 63 multiparous women attending the Gynecology/ Obstetrics and Pediatrics service of the Heitor Beltrão CMS (Rio de Janeiro-RJ) in the period August 2003 to January 2004. In order to understand the meanings of the vaccination, a test of the ideas evoked by the word "vaccine" and a questionnaire were applied.

Results: it was identified that mothers associated immunization essentially with "prevention" and "protection". The ideas of "good", "careful" and "responsible" identified in the peripheral representations system led them to place these acquired cognitive concepts in the concrete context of their everyday lives, thereby ensuring that the vaccination calendar was observed. These feelings are strictly related to the epidemiological discourse that characterizes immunization as a specific act of protection.

Conclusions: the Brazilian experience of child vaccination, with almost $90 \%$ observance achieved in little more than two decades, suggests that an active and informed point of view on the part of the beneficiaries of immunization has replaced any misunderstandings or resistance that mothers may have had with regard to vaccination. A specific set of political, economic, cultural and technological factors-both national and international-were identified as being involved in the provision of immunobiological services by the Brazilian health network and these are reflected in the present degree of observance of the vaccination calendar.

Key words Vaccination, Health education
Maria Vicencia Pugliesi 1 Luiz Fernando Rangel Tura 2 Maria de Fátima Siliansky de Andreazzi 3
${ }^{1}$ Centro Municipal de Saúde Heitor Beltrão. Secretaria Municipal de Saúde do Rio de Janeiro. Rua Desembargador Izidro, 144. Rio de Janeiro, RJ, Brasil. CEP 20.521-160.

E-mail: mvpugliesi@terra.com.br.

2,3 Departamento de Medicina Preventiva. Faculdade de Medicina. Universidade Federal do Rio de Janeiro, Rio de Janeiro, Brasil.

\section{Resumo}

Objetivos: levantamento dos fatores envolvidos na significativa observância das mães ao calendário vacinal do Programa Nacional de Imunizações.

Métodos: amostra de 124 gestantes, divididas em dois grupos: 61 gestantes nuliparas e 63 multiparas, entre as que frequentaram o serviço de Ginecologia/ Obstetrícia e Pediatria do CMS Heitor Beltrão (Rio de Janeiro-RJ) no período de agosto de 2003 a janeiro de 2004. Para apreender os sentidos de vacinação, foram utilizados o teste de evocação "vacina" e um questionário.

Resultados: identificou-se que as mães associaram imunização essencialmente a "prevenção" $e$ "proteção". As percepções "bom”, "cuidado" $e$ "responsabilidade" identificadas no sistema periférico da representação as impelem concretizar no cotidiano essas cognições adquiridas, garantindo o cumprimento do calendário vacinal. Tais sentidos relacionam-se estreitamente com o discurso da Epidemiologia que caracteriza as ações de imunização como ações de proteção específica.

Conclusões: a experiência com vacinação de crianças no Brasil, com observância próxima a 90\%, alcançada em pouco mais de duas décadas, indica que uma visão ativa e consciente dos benefícios das imunizações substituiu possiveis desconhecimentos ou resistências por parte das mães em relação à vacinação. Identificou-se que um conjunto específico de fatores políticos, econômicos, culturais, tecnológicos - nacionais e internacionais - estão envolvidos na oferta de imunobiológicos à rede de saúde brasileira e contextualizam a atual observância ao calendário vacinal.

Palavras-chave Vacinação, Educação em saúde 


\section{Introdução}

A vacinação, particularmente de lactentes e de crianças na primeira infância, vem se constituindo em relevante ação de prevenção de doenças infectocontagiosas, que em um passado recente levavam ao óbito e a graves sequelas milhares, e mesmo milhões, de crianças no Brasil e no mundo. Porém, cerca de dois milhões de crianças ainda morrem anualmente por doenças evitáveis ${ }^{1}$ com uma a três doses de vacinas.

O calendário vacinal é dinâmico e condicionado por fatores individuais e epidemiológicos, ${ }^{2}$ além dos relativos ao desenvolvimento científico e de ordem econômica. ${ }^{3}$ Assim, no Brasil além das vacinas implantadas inicialmente pelo Programa Nacional de Imunização (PNI), outras foram progressivamente agregadas.

As ações de vacinação, institucionalizadas no PNI, têm sido recentemente incorporadas à cultura popular dos cuidados referentes à saúde das crianças. 4

Simoes 5 assinala que "a experiência com a varíola mostrou que a erradicação de uma doença é possível quando é atingida e mantida ampla cobertura com uma vacina eficaz" (p. 196).

Segundo dados do PNI, em 1978 a cobertura vacinal no Brasil atingia apenas cerca de $40 \%$ das crianças e, em 1999, a cobertura em menores de um ano chegou próximo a $90 \%$. Entre as vacinas de rotina, também em menores de um ano, o país vem alcançando níveis próximos a $100 \%$ de cobertura vacinal, a partir de 1995, contra as formas graves de tuberculose, com a aplicação da vacina BCG (Bacilo de Calmette-Guérin) no neonato. 6

Há importantes diferenças regionais nos índices de morbimortalidade e também de cobertura vacinal. Duarte et al. ${ }^{7}$ observaram que em mais de $70 \%$ dos municípios de Estados como Rio de Janeiro, São Paulo, Espírito Santo, Tocantins e Sergipe foram alcançadas coberturas vacinais para a tríplice DTP (Difteria, Tétano e Pertussis) acima de 95\% em 2000. Nos Estados do Pará, Maranhão e Amazonas menos de $30 \%$ dos municípios apresentaram cobertura de DPT superior a 95\%.

Com a significativa contribuição da cobertura vacinal, houve redução da mortalidade infantil mas a desigualdade social se expressa com força dramática no número de óbitos que ainda ocorrem. Se todas as regiões brasileiras alcançassem a taxa de mortalidade infantil da Região Sul (de 17,1 por 1000 nascidos vivos), a mais desenvolvida região do país, "haveria uma redução de 46,2\% nas mortes de menores de um ano, o que representaria a não ocor- rência de 43.439 óbitos infantis a cada ano.”(p. 66). ${ }^{7}$

Os altos índices de observância das mães às ações de imunização do PNI, um dos mais significativos na área de saúde, verificados no Brasil atualmente, motivou a nossa tentativa de entender as mudanças ocorridas com a imunização.

Nessa perspectiva, a teoria das representações sociais (TRS) é um instrumental diferenciado, com aplicação em trabalhos de pesquisa, com especial interesse na área de saúde, ${ }^{8}$ ao buscar junto a grupos, setores e segmentos da população apreender sua experiência, voz e saberes não instituídos como conhecimento acadêmico, mas dentro de um contexto social determinado.

A TRS articula um conjunto de conceitos para assimilar os elementos cognitivos e sociais envolvidos nas representações.

Este artigo tem como objetivo caracterizar as representações sociais sobre a vacinação, elaboradas por mães usuárias de um serviço público de saúde.

\section{Métodos}

O trabalho de campo teve início com observação sistemática, três vezes/semana por um período de seis meses (agosto de 2003 a janeiro de 2004), na sala de vacinas do Centro Municipal de Saúde Heitor Beltrão, na cidade do Rio de Janeiro, possibilitando uma relação de conhecimento com o objeto, em um contexto de relações sociais e de poder. ${ }^{9}$

Instituiu-se um diário de campo para anotações julgadas relevantes, tendo-se cuidado para que o trabalho não fosse confundido com uma inspeção ou avaliação do serviço prestado na unidade.

Procurou-se ficar alerta para a tendência que pode existir, e por vezes ocorre, de as pessoas funcionários e mães - procurarem agir, responder como acreditam que o observador espera que digam. ${ }^{9}$ Foram observadas a dinâmica da assistência e efetivação das ações de imunização, bem como relações que se estabelecem entre as mães e o serviço de saúde; e entre elas e os fillhos no momento da aplicação da vacina. Esse procedimento permitiu uma aproximação mais longa e informal com os sujeitos, contribuindo para uma interação com o ambiente e um estudo preliminar do campo. Essa experiência subsidiou a construção do questionário, que foi aplicado às mães.

Num segundo momento, foi aplicado o teste de evocação e questionário já usado em vários trabalhos, ${ }^{10-12}$ procedendo-se um contato com a área de Ginecologia/Obstetrícia, na qual se realizou a maior parte dos testes e questionários e também com a Pediatria, onde pequena parte dos procedimentos 
foi aplicada.

O conjunto estudado de 124 gestantes, divididas em dois grupos, 61 gestantes nulíparas e 63 mulheres multíparas que frequentavam o Serviço de Ginecologia/Obstetrícia e Pediatria da Unidade, foi constituído de uma amostra aleatória simples com correção para populações finitas, levando-se em consideração um índice de respostas de no mínimo $20 \%$, precisão de $6 \%$ e poder de teste de $80 \%$.

Após a apresentação do projeto às mães e com o intuito de levantar o conteúdo das representações que elas têm da vacinação dos filhos, foram utilizados o teste de evocação e um questionário. Uma associação livre com a palavra vacina foi sugerida na aplicação do teste de evocação, procedimento que tem apresentado significativa relevância para a identificação das representações sociais, bem como de sua organização.13-15 Para isso era apresentada a questão: "Quais as quatro primeiras palavras ou expressões que passam pela sua cabeça quando ouve falar de vacina?" Em seguida, solicitava-se que marcassem as duas palavras, entre as citadas, que considerassem as mais importantes.

Na sequência, aplicava-se um questionário com perguntas fechadas e abertas sobre idade, estado de origem, escolaridade, ocupação, estado civil (com companheiro ou sem companheiro), número de filhos, número de pessoas nas residências e o número de cômodos.

Procurou-se identificar também atitudes, experiência, conceitos, significados do processo de vacinação das crianças.

Analisaram-se os resultados do teste de evocação, procedendo-se ao levantamento do conjunto de expressões, categorizadas e computadas de forma a evidenciar as mais significativas. Estes resultados foram questionados e testados por meio de uma estratégia que visa à confirmação (ou não) da centralidade desses elementos. No momento seguinte, a partir do questionário, foram discutidas as questões fechadas e procedeu-se a uma análise de conteúdo das questões abertas com a intenção de subsidiar o estudo das representações sociais e confirmar os elementos estruturais identificados na representação, além de avaliar as relações que as gestantes e mães pesquisadas estabelecem com o objeto.

Após a aplicação do teste, buscou-se estimar a força de expressividade que cada conteúdo apresenta, para o grupo em estudo, por meio de uma avaliação quantitativa de frequência de emissão das palavras. Levantando-se a frequência de evocações e a ordem média de evocação para avaliar os diversos elementos evocados (aspecto coletivo) e a ordem de evocação desses elementos (aspecto individual), segundo Vergès. 15 Para isso foi calculada a frequência de evocações somando-se o número de vezes em que a palavra era evocada nas diversas posições; a ordem média de evocação foi obtida atribuindo-se o peso 1 quando era evocada em primeiro lugar, peso 2, quando evocada em segundo lugar e assim sucessivamente até incluir as ordens em que a palavra foi evocada. Em seguida, dividiuse o somatório dos produtos obtidos pelo somatório das frequências da palavra citada nas diversas posições, obtendo-se, assim, a ordem média de evocação (OME) do elemento. ${ }^{14}$

Para obter a estrutura da representação social da vacina, os dados eram distribuídos em um gráfico de dispersão. Neste gráfico o cruzamento das linhas indicativas da média de frequência e da média das ordens médias de evocação gera um diagrama de quatro quadrantes. As evocações de maior frequência e mais rapidamente evocadas estarão dispostas no quadrante superior esquerdo e o oposto, no quadrante inferior direito. Os prováveis componentes do núcleo central serão encontrados, portanto, no quadrante superior esquerdo e aqueles do quadrante inferior direito indicam as expressões do sistema periférico, indicativas de maior instabilidade e fluidez.

As respostas abertas tiveram os conteúdos tratados pela análise categorial temática, conforme preconizado por Bardin. 16

Cabe o registro de que este trabalho contemplou as premissas da resolução 196/1996 do Conselho Nacional de Saúde. 17 A pesquisa foi aprovada pelo Comitê de Ética do IESC/UFRJ.

\section{Resultados e Discussão}

\section{Caracterização das mães}

No conjunto de mães e gestantes entrevistadas (Tabela 1), a idade variou de 14 a 41 anos, a moda situada entre 20 a 29 anos, correspondendo a 52,4\% do grupo; também nesta faixa encontra-se a moda de idade para as duas subamostras: multíparas e nulíparas (Tabela 1). A média de idade encontrada foi de 24,09 anos; entretanto, 29,9\% corresponde à faixa etária de 14 a 19 anos.

Observou-se um expressivo número de gestantes, principalmente, e mães adolescentes. Do total das gestantes nulíparas, quase a metade $(44,3 \%)$ era adolescente. No conjunto das adolescentes nulíparas, quase a metade $(44,4 \%)$ apresentava entre 14 e 19 anos. Observou-se, também, que 49,19\% eram gestantes nulíparas e que entre as multíparas, $87,3 \%$ 
tinham um ou dois filhos; $12,7 \%$ tinham três ou mais (Tabela 2).

Estudos têm mostrado um grande aumento da taxa de fecundidade entre adolescentes, no país, com um incremento de $26 \%$ na gravidez na faixa de 15 a 19 anos entre os anos de 1970 e 1991, sendo a fecundidade das jovens pobres muito maior que as de maior nível socioeconômico. ${ }^{18}$

Tabela 1

Gestantes e mães segundo idade em anos e número de gestações.

\begin{tabular}{lrrrrrr}
\hline Idade (anos) & \multicolumn{2}{c}{ Nulíparas } & \multicolumn{2}{c}{ Multíparas } & \multicolumn{2}{c}{ Total } \\
\cline { 2 - 7 } & $\mathrm{n}$ & $\%$ & $\mathrm{n}$ & $\%$ & $\mathrm{n}$ & $\%$ \\
\hline $14-19$ & 27 & 44,3 & 10 & 15,9 & 37 & 29,9 \\
$20-29$ & 33 & 54,1 & 32 & 50,8 & 65 & 52,4 \\
$30-39$ & 1 & 1,6 & 19 & 30,1 & 20 & 16,1 \\
40 ou mais & - & - & 2 & 3,2 & 2 & 1,6 \\
Total & 61 & 100,0 & 63 & 100,0 & 124 & 100,0 \\
\hline
\end{tabular}

Tabela 2

\begin{tabular}{|c|c|c|c|c|}
\hline \multirow[t]{2}{*}{ Filhos } & \multicolumn{2}{|c|}{ Nulíparas } & \multicolumn{2}{|c|}{ Multíparas } \\
\hline & $\mathrm{n}$ & $\%$ & $\mathrm{n}$ & $\%$ \\
\hline Nenhum & 61 & 100,0 & - & - \\
\hline 1 & - & - & 33 & 52,4 \\
\hline 2 & - & - & 22 & 34,9 \\
\hline 3 ou mais & - & - & 08 & 12,7 \\
\hline Total & 61 & 100,0 & 63 & 100,0 \\
\hline
\end{tabular}

\section{As representações de vacina e sua estrutura}

Quanto às representações sociais verificou-se que, diante da palavra 'vacina', as mães e gestantes realizaram 314 evocações, com um total de 54 palavras diferentes. Analisando-se o conjunto de expressões evocadas, procedeu-se a um levantamento de sinônimos e categorização por aproximação semântica desse material, alcançando-se um corpus de 31 categorias. As dez palavras evocadas com maior frequência foram: prevenção, saúde, proteção, importante, responsabilidade, doença, cuidado, bom, criança e combate que corresponderam a $84,7 \%$ do total de evocações.

A frequência média de evocação e a média das ordens médias de evocação, calculada segundo Vergès, 15 foi de 36 e 1,95 respectivamente. Os elementos "prevenção" e "proteção" apareceram com frequência maior ou igual a 36 e sendo a OME menor do que $1,95 \mathrm{e}$, assim, compõem o quadrante superior esquerdo, correspondendo ao núcleo central das representações do grupo em estudo. Os elementos "bom", "cuidado" e "responsabilidade" apareceram com uma frequência menor de 36 e ordem OME maior ou igual a 1,95, compondo o quadrante inferior direito, referente ao sistema periférico. E, finalmente, encontram-se os elementos "doença" e "importante", que foram evocados com uma frequência menor que 36 e OME menor que 1,95, e "saúde", em situação oposta, compondo o sistema intermediário ou periferia próxima (Tabela 3).

O núcleo central, "estável, coerente, consensual e historicamente determinado" (p.13), dá significado 
Estrutura da representação social de vacina.

\begin{tabular}{|c|c|c|c|c|c|c|}
\hline \multirow{2}{*}{ N } & \multicolumn{3}{|c|}{$\mathrm{OME}<1,95$} & \multicolumn{3}{|c|}{$\mathrm{OME} \geq 1,95$} \\
\hline & Elementos & $\mathrm{n}$ & OME & Elementos & $\mathrm{n}$ & $\mathrm{OME}$ \\
\hline \multirow{3}{*}{$\geq 36$} & Prevenção & 89 & 1,89 & & & \\
\hline & & & & Saúde & 42 & 1,97 \\
\hline & Proteção & 36 & 1,80 & & & \\
\hline \multirow{3}{*}{$<36$} & Doença & 18 & 1,55 & Bom & 10 & 2,50 \\
\hline & & & & Cuidado & 14 & 2,35 \\
\hline & Importante & 20 & 1,60 & Responsabilidade & 20 & 2,00 \\
\hline
\end{tabular}

OME $=$ Ordem Média de Evocação.

à representação e a organiza internamente. 19 A sua supressão descaracteriza a representação; a sua modificação implica em mudança da representação social e a sua expressão permite conhecer a experiência vivenciada pelo grupo em questão. Abric 20 pondera ainda que:

\footnotetext{
É preciso considerar também que a centralidade de um elemento não pode ser atribuída somente por critérios quantitativos. Ao contrário, o núcleo central possui, antes de tudo, uma dimensão qualitativa. Não é a presença maciça de um elemento que define sua centralidade, mas sim o fato que ele dá significado à representação. (p.31)20
}

Sobre esse aspecto, Moliner21 enfatiza que as características quantitativas do núcleo central decorrem exatamente de sua centralidade, "que é fundamentalmente qualitativa" (p.203), de significação. E, ainda, "se a centralidade qualitativa implica propriedades quantitativas, o inverso não é sempre verdadeiro" (p.205).
Estabelecida a possível estrutura das representações sociais de vacina, procedeu-se, a seguir, a uma avaliação da centralidade ou do poder simbólico dos elementos que estruturam essa representação, 10,15,21 buscando por meio do teste da dupla negação questionar a consistência das evocações realizadas. Esse procedimento permite estimar o valor simbólico dos elementos componentes da representação e identificar a hierarquização dos mesmos. 19 Parte-se da proposição de que os elementos do núcleo central são imprescindíveis para a representação e sua refutação acarretaria a perda de significação da representação.

Assim, em quarenta mães, escolhidas aleatoriamente nos serviços de Obstetrícia/Ginecologia e no de Pediatria, foi feito o teste de questionamento dos elementos componentes do núcleo central e sistema periférico da representação em estudo: "prevenção", "saúde", "proteção", "cuidado", "bom”, "responsabilidade". Os resultados obtidos podem ser observados na Tabela 4.

Tabela 4

Teste de Questionamento.

\begin{tabular}{llrl}
\hline Elemento & N & $\%$ & IC 95\%* \\
\hline Prevenção & 39 & 97.5 & {$[85.26-99.86]$} \\
Proteção & 39 & 97.5 & {$[85.26-99.86]$} \\
Cuidado & 40 & 100.0 & {$[89.08-100.00]$} \\
Bom & 40 & 100.0 & {$[89.08-100.00]$} \\
Responsabilidade & 40 & 100.0 & {$[89.08-100.00]$} \\
\hline
\end{tabular}

${ }^{*}$ IC $95 \%=$ Intervalo de confiança a $95 \%$. 
$\mathrm{Na}$ avaliação do teste de dupla negação, são considerados como confirmados os elementos que alcançam a proporção de dupla negação igual ou maior do que 70\% (IC95\%), isto é, os sujeitos não reconhecem o objeto sem a presença do elemento avaliado. Assim, os elementos estruturais da representação questionados foram confirmados (Tabela 4).

$\mathrm{Na}$ resposta às perguntas abertas, os elementos "prevenção" e "proteção" apresentaram-se novamente com força e significação para as entrevistadas, evidenciando uma contextualização histórica específica, bastante diversa da que envolveu a Revolta da Vacina de 1904 e, por outro lado, o estabelecimento de um hábito, uma tradição que vem repassando de geração a geração nas últimas décadas. Ao responderem por que traziam seus filhos à vacinação, mães assim se expressavam:

[...] para prevenir das doenças. Tanto é que minha mãe cuidou direitinho dessa parte e eu não tive doença nenhuma. E a gente aprende com nossa mãe. É coisa que a gente cresce já sabendo que é certo. (27 anos; fluminense do interior - Campos, há quatro anos na cidade do Rio; ensino médio completo; cabeleireira) - 91

No intuito de explorar possíveis sentidos que as entrevistadas suscitavam com o elemento "prevenção", utilizou-se um dicionário da língua portuguesa. Para prevenção, foram encontrados significados como: ato ou efeito de prevenir-se, modo de ver antecipado, precaução, cautela. Para prevenir: preparar, dispor de maneira que evite (dano, mal), evitar, antecipar-se, precaver-se, armarse, premunir-se, entre outros. 22

Em outras falas explicitaram o entendimento que têm acerca da "proteção" que as vacinas conferem às crianças:

Porque a criança fica protegida, você fica mais segura. É importante que todas as mães tivessem essa responsabilidade. (33 anos; cearense, há dez anos no Rio; $5^{\text {a }}$ série do ensino fundamental, empregada doméstica) - 69

A busca ao dicionário 22 ofereceu para o elemento "proteção" sentidos como: ato ou efeito de protegerse, abrigo, resguardo, auxílio, amparo. Para "proteger": tomar a defesa, apoiar, preservar do mal, defender.

Verificou-se, por outro lado, que os elementos "prevenção" e "proteção", identificados como núcleo central das representações que as mães e gestantes têm da vacinação de seus filhos, guardam referência, sintonia, pode-se dizer estreita, com o discurso da Epidemiologia, que define as ações de imunização como ações de proteção específica, no âmbito da prevenção primária.

Para os elementos do sistema periférico, foram encontrados no dicionário 22 os seguintes sentidos: "cuidado" - precaução, cautela, desvelo, zelo, encargo, inquietação de espírito; "bom" - que tem todas as qualidades adequadas à sua natureza ou função, benigno, perfeito, completo; "responsabilidade" - qualidade ou condição de responsável; responsável - que responde pelos próprios atos ou pelos de outrem.

Elementos do sistema periférico também foram revelados nas falas das multíparas, como o cuidado diário e o senso de responsabilidade que atribuem às mães, suplantando possíveis entraves emocionais, de medo ou pena, ou mesmo materiais, que pudessem dificultar a observação do calendário vacinal. São percepções ligadas às experiências pessoais, inclusive as funções sociais que atribuem à condição de ser mãe, manifestando sua ancoragem no cotidiano:

[...] quem ama cuida, e a vacina é uma forma de cuidar. Acho que nem é preciso falar. (23 anos, fluminense, ensino médio completo, sem atividade remunerada) - 82

Em ação há mais de 30 anos, o PNI disponibiliza na rede básica de atenção, em cerca de 26 mil postos de rotina de vacinação, uma oferta organizada, de fácil acesso, cotidiana, de um conjunto de imunizantes. Envolve em algumas ocasiões, como nos Dias Nacionais de Vacinação, um processo efetivamente ativo, ampliado, com o trabalho de contatar as famílias, chegar às crianças, efetuado pelos profissionais das unidades de saúde, por agentes comunitários.

Os Dias Nacionais de Vacinação se sucedem desde 1980, em duas etapas, com campanhas impactantes de mídia, em rede de comunicação nacional, com a participação de personagens conhecidos do grande público, que possam inspirar confiança, admiração, respeito.

Unidades de saúde em milhares de municípios do país foram, portanto, equipadas para oferecer esse serviço. Nos Dias Nacionais de Vacinação, mesmo unidades que não oferecem o serviço rotineiramente acabam se integrando a esta rede de oferta de imunizantes, assim como escolas e entidades. Em Dias Nacionais de Vacinação contra a Poliomielite, chegam a ser mobilizadas mais de 400 mil pessoas, entre servidores da saúde e voluntários, em 117 mil postos para a vacinação em todo o país, segundo informe da Secretaria de Vigilância à Saúde. 23

Ressalte-se ainda a experiência de milhares de 
famílias que não mais vivenciaram as angústias provocadas por algumas afecções anteriormente identificadas num espectro de "doenças próprias da infância", que poderiam levar seus filhos ao óbito ou a graves sequelas. Várias falas se referiram a essa experiência, que sinaliza mais uma vez a contextualização histórica e social da representação:

[...] porque sem vacina a criança não fica legal. Eu tenho um irmão que não tomou vacina e ficou com paralisia infantil, que agora não dá mais por causa das vacinas. (24 anos, cearense, $5^{\mathrm{a}}$ série do ensino fundamental, sem atividade remunerada) -68

Moscovici24 avalia que há uma relação dinâmica que leva o grupo em questão a incorporar saberes antes incomuns ao cotidiano: "isso só é possível se fizermos passar, como através de vasos comunicantes, linguagens e saberes de regiões onde existe abundância para regiões onde predomina a escassez e vice-versa" (p.60).

Já no processo de observação, percebeu-se que as mães têm uma avaliação positiva dos benefícios que a imunização proporciona aos filhos, ao associála à prevenção de doenças. Mesmo que algumas se ressentissem com a dor que envolve a aplicação de alguns imunizantes, elas se mostraram compensadas pelo benefício que reconheciam implícito ao ato.

Ao se identificar os elementos "prevenção" e "proteção" como componentes do núcleo central das representações sociais das gestantes e mães acerca de vacina das crianças, pôde-se avaliar que esses sentidos contribuem, de forma efetiva, para a significativa observância ao calendário vacinal observada atualmente. E, como foi visto anteriormente, as representações sociais orientam a prática dos indivíduos e grupos que as elaboram, interferindo no cotidiano deles, dirigindo suas ações.

A percepção do objeto é submetida a um processo de interiorização, por vezes de transformação, para que resulte "num conhecimento que a maioria das pessoas utiliza em sua vida cotidiana" (p.50). ${ }^{24}$ Observou-se, por exemplo, que as gestantes e mães em questão se apropriaram da cognição "prevenção", incorporando-a ao universo próprio, cotidiano, de cuidado das crianças.

A prática da vacinação e o processo que a envolve, incluindo a atuação dos serviços de saúde, as campanhas de mídia e a experiência apreendida com tal prática, influenciaram a elaboração das representações que as mães têm sobre a vacinação das crianças e, reciprocamente, tais representações vêm orientando sua prática, de tal modo que uma gestante aconselhava:
[...] que todas não deixem de vacinar. Minha mãe teve dez filhos, levava os dez para vacinar, nunca deixou de levar. Eu tenho o cartão, bonitinho... (24 anos, pernambucana, há três anos no Rio, $7^{\text {a }}$ série do ensino fundamental, empregada doméstica) -26

Há três gerações, ao menos, desde a implantação do PNI, as mães acumularam conhecimentos que as impelem à observação do calendário vacinal nos níveis expressivos em que hoje são verificados. E hoje o fazem de maneira consciente, mobilizadas por asserções análogas às que o saber acadêmico preconiza.

Em uma nova etapa de análise, procurou-se identificar possíveis diferenças entre as estruturas da representação de vacina para nulíparas e multíparas. Foram observadas algumas diferenças nas estruturas das representações construídas por elas.

Identificou-se no núcleo central das multíparas somente o elemento "proteção", com frequência igual a 25 e OME igual a 1,88 . Observou-se que "prevenção", com frequência igual a 47 e OME igual a 2, passou a compor o sistema intermediário, ocupando o quadrante superior direito; ao mesmo tempo, "saúde", com frequência igual a 20 e OME igual a 1,65, também mudou de posição, deslocandose para o quadrante inferior esquerdo. Quanto ao sistema periférico, verificou-se que passou a ser composto por "cuidado", frequência igual a 12 e OME igual a 2,33, e "responsabilidade", frequência igual a 12 e OME igual a 2,16, constatando-se o desaparecimento do elemento "bom" (Tabela 5).

Entre as nulíparas, também, foram observadas modificações na estrutura da representação de vacina. O núcleo central passou a ser composto somente pelo o elemento "prevenção", que se apresentou com maior saliência, com frequência igual a 42 e OME igual a 1,78. Foram verificadas, ainda, modificações significativas na composição dos sistemas intermediário e periférico: com frequências iguais a 13,11 e 13, e OME iguais a 1,46, 1,72 e 1,76 , encontram-se os elementos "doença", "importante" e "proteção", respectivamente, que apareceram situados no quadrante inferior esquerdo; "saúde", com frequência igual a 22 e OME igual a 2,27 , desloca-se para o quadrante superior direito, sua posição quando se estudou a amostra como um todo. Curiosa e significativamente não foram observados elementos periféricos na estrutura das representações de vacina no grupo das gestantes nulíparas (Tabela 6).

Para Sá, 10 é no sistema periférico das representações sociais que se observa "a interface com as questões práticas da vida cotidiana” (p.82) ou as 
Tabela 5

Estrutura da representação social de vacina das multíparas.

\begin{tabular}{|c|c|c|c|c|c|c|}
\hline $\mathbf{N}$ & \multicolumn{3}{|c|}{ OME $<2,00$} & \multicolumn{3}{|c|}{ OME $\geq 2,00$} \\
\hline$\geq 22$ & Proteção & 25 & 1,88 & Prevenção & 47 & 2,00 \\
\hline$<22$ & & & & Responsabilidade & 12 & 2,16 \\
\hline
\end{tabular}

OME= Ordem Média de Evocação.

Tabela 6

Estrutura da representação social de vacina das nulíparas.

\begin{tabular}{|c|c|c|c|c|c|c|}
\hline \multirow{2}{*}{$\mathbf{N}$} & \multicolumn{3}{|c|}{ OME $<1,95$} & \multicolumn{3}{|c|}{ OME $\geq 1,95$} \\
\hline & Elementos & $\mathrm{n}$ & OME & Elementos & $\mathrm{n}$ & OME \\
\hline \multirow[t]{2}{*}{$\geq 22$} & Prevenção & 42 & 1,78 & Saúde & 22 & 2,27 \\
\hline & Doença & 13 & 1,46 & & & \\
\hline \multirow[t]{2}{*}{$<22$} & Importante & 11 & 1,72 & & & \\
\hline & Proteção & 13 & 1,76 & & & \\
\hline
\end{tabular}

OME= Ordem Média de Evocação.

modulações individuais, como assinala Flament. 25 Enquanto os elementos centrais envolvem prescrições absolutas ou incondicionais, os elementos periféricos são reconhecidos como prescrições condicionais, mais ligadas ao dia-a-dia, ao contexto do momento em que a prática social é observada. $\mathrm{O}$ sistema periférico revela indícios, indicações das condições da situação atual. É condicionado pelos fatos presentes e vulnerável às intercorrências da experiência vivenciada pelo grupo. Experiências e práticas, por sua vez, que revelam as especificidades do grupo que suscitam (ou não, como neste caso) tais elementos.

As gestantes nulíparas não vivenciaram a experiência da vacinação de seus filhos, e assim se explica a lacuna observada em seu sistema periférico: efetivamente, não foram encontradas expressões cotidi- anas de uma vivência que ainda não ocorreu.

Por outro lado, fazem parte do sistema periférico das multíparas os elementos: "bom", "cuidado" e "responsabilidade", cognições condicionadas pelo fato de, no seu cotidiano, já terem experimentado a efetivação da imunização em seus filhos, com o conjunto de sentidos e os conhecimentos que tal prática lhes desvelou.

Quanto ao núcleo central, podemos avaliar também que as multíparas têm uma experiência mais concreta com os filhos que já receberam imunização e não apresentaram as doenças, ficando assim "protegidos". Já as nulíparas não passaram, pessoalmente, por essa experiência tendo evocado com maior frequência uma palavra de ordem mais geral, como "prevenção". 


\section{Conclusões}

Neste estudo foram constatados os sentidos de "prevenção" e "proteção" para vacina. Essa observação torna-se mais relevante se considerado o contexto em que, nos últimos trinta anos, principalmente, envolveu a instituição do PNI, as diretrizes e apoios financeiros internacionais, os Dias Nacionais de Vacinação e toda a sua veiculação nos meios de comunicação, a ampliação da rede básica e implementação do SUS, garantindo a oferta de imunizantes diariamente em diversas unidades de vacinação na rede de saúde e a receptividade das mães com sua experiência acerca dos benefícios da vacinação.

Os contextos mais imediatos, reveladores da realidade concreta, são expressos no sistema periférico; os elementos "bom", "cuidado", "responsabilidade", neste caso. São elementos adaptativos, condicionais, avaliativos, contemplam uma variedade de situações do cotidiano e guardam uma relação dialética com os do núcleo central. Assim, são entendidos como condicionais na medida em que, em contraste, os elementos do núcleo central são prescrições absolutas, incondicionais, essenciais. Estão, portanto, mais ligados ao dia-a-dia das mães: as representações "bom", "cuidado" e "responsabilidade" determinam a tomada de posição mais imediata; a decisão de, naquele dia, naquele momento, levar os filhos a vacinar, concretizando o entendimento mais essencial que têm da vacinação, os sentidos de "prevenção" e "proteção".

O subconjunto de elementos da representação, reconhecido como núcleo central, hierarquiza, portanto, um conjunto de informações, experiências, crenças, normas, valores, atitudes, práticas e relações que as mães ou futuras mães estabelecem no processo de vacinação: os elementos do seu sistema periférico. Para o grupo em estudo, hierarquizam relações que envolvem o discernimento de

\section{Referências}

1. WHO (World Health Organization). State of the World's Vaccines and Immunization. Geneva: World Health Organization, 2002. [on line] [2004 Jun 19]. Disponível em: http://www.unicef.org/publications/pub_sowvi_en.pdf

2. Carvalho ES, Weckx LY. Calendário vacinal: dinâmica e atualização. J Pediatria. 1999; 75 (Supl. 1): 149-54.

3. Gadelha C, Temporão JG. A Indústria de Vacinas no Brasil: Desafios e Perspectivas. Rio de Janeiro: Banco Nacional de Desenvolvimento Econômico e Social; 1999.

4. Correia LL, MacAuliffe JF. Saúde Materno-infantil. In: escala de importância das ações de imunização na prática diária de cuidado que têm com os filhos, de experiências pessoais e familiares, de contato com o sistema de saúde, com os meios de comunicação, com visões mais totalizantes (ou não) e expectativas de saúde, com noções (ou privação, ausência) de direitos sociais, com os entraves econômicos de sua inserção social. Esses elementos estão mais diretamente ligados ao contexto imediato dessas mães, integradores das vivências cotidianas, individuais e coletivas, contudo condicionados pelos sentidos mais essenciais que atribuem à vacinação: "prevenção" e "proteção".

Em alguns estudos, no início da década de 1980 e mesmo no final da década de 1990,26,27 encontraram-se avaliações que indicavam um "escasso" conhecimento das mães acerca da vacinação dos próprios filhos. Seria, assim, o pouco conhecimento sobre vacinas ou um conjunto de crenças os fatores determinantes para a limitada expansão da cobertura no início da implantação do PNI? Nesse sentido, a ênfase a ser colocada para ampliar os índices de cobertura constatados à época estaria basicamente em envidar mais e maiores esforços no sentido de aumentar o "conhecimento" das mães? E em 1998, com níveis de cobertura próximos a $90 \%$, continuariam escassos os seus conhecimentos?

A presente pesquisa indicou outros caminhos. Os elementos "prevenção" e "proteção" encontrados como núcleo central das representações que as mães têm acerca da vacinação apresentam sintonia com o discurso acadêmico da Epidemiologia, sugerindo que uma visão ativa e consciente dos benefícios das imunizações substituiu possíveis desconhecimentos ou resistências que possuíssem em relação à vacinação. Um conjunto de fatores políticos, econômicos, culturais e tecnológicos determinou as mudanças hoje verificadas na observância das mães ao calendário vacinal.
Rouquayrol MZ e Almeida Filho N, editores. Epidemiologia \& Saúde. Rio de Janeiro: Medsi; 1999. p. 375-403.

5. Simoes EAF. Imunização. In: Hay WW, editor. Diagnóstico e tratamento em pediatria. Rio de Janeiro: Editora Guanabara Koogan; 1997. p. 196-7

6. Brasil. Ministério da Saúde. Secretaria de Vigilância em Saúde. Programa Nacional de Imunizações. 2001. [on line] [2004 Jun 11]. Disponível em: http://dtr2001.saude.gov.br/ svs/imu/imu01.htm 
7. Duarte EC, Schneider MC, Paes-Sousa R, Ramalho WM; Sardinha L, Silva JB, Castillo-Salgado C. Epidemiologia das desigualdades em saúde no Brasil: um estudo exploratório. Brasília: Organização Pan-Americana de Saúde; 2002.

8. Sá CP, Arruda A. O estudo das representações sociais no Brasil. Rev Ciênc Hum. 2000; n. especial: 11-31.

9. Tura MLR. A observação do cotidiano escolar. In: Zago N; Carvalho MP; Vilela RAT, organizadoras. Itinerário de pesquisa: perspectivas qualitativas em sociologia da educação. Rio de Janeiro: DP\&A; 2003. p.183-205.

10. Camargo BV. Sexualidade e representações sociais da AIDS. Rev Ciênc Hum. 2000; Esp. Temática: 97-110.

11. Tura LFR, Madeira MC, Gaze R. Representações sociais das hepatites virais e suas implicações nas práticas educativas de prevenção. Cad Saúde Coletiva. 2002; 10: 195-213

12. Abric JC. Méthodologie de recueil des représentations sociales. In: Abric JC, organizador. Pratiques sociales et représentation. Paris: PUF; 1994. p. 59-82

13. Sá CP. Núcleo central das representações sociais. Petrópolis: Vozes; 1996.

14. Tura LFR. Aids e estudantes: a estrutura das representações sociais. In: Jodelet D; Madeira MC, organizadoras. Aids e representações sociais: à busca de sentidos. Natal: EDUFRN; 1998. p.121-54.

15. Vergès P. Approche du noyau central: propriété quantitatives et structurales. In: Guimelli C, organizador. Structures et transformations des représentations sociales. Lausanne: Delachaux et Niestlé; 1994. p. 233-53.

16. Bardin L. L'analyse de contenu et de la forme des comunications. In: Moscovici S, Buschini F. Les méthods des sciences humaines. Paris: PUF; 2003. p. 243-70.

17. Brasil. Conselho Nacional de Saúde: Resolução n. 196/96, de 10 de outubro de 1996. Cadernos de Ética em Pesquisa. 1998; 1: 34-42.

Recebido em 29 de janeiro de 2009

Versão final apresentada em 15 de julho de 2009

Aprovado em 30 de setembro de 2009
18. Cannon LRC. Saúde e desenvolvimento da juventude brasileira: construindo uma agenda nacional. Brasília, DF: Ministério da Saúde/Unicef/OPAS/OMS; 1999.

19. Abric JC. L'analyse structurale des représentations sociales. In: Moscovici S et Buschini F, organizadores. Les méthodes des sciences humaines. Paris: PUF; 2003. p. 375-92

20. Abric JC. A abordagem estrutural das representações sociais. In: Moreira ASP, Oliveira DC, organizadores. Estudos interdisciplinares de representação social. Goiânia: AB; 1998. p. 27-38.

21. Moliner P. Les méthodes de répérage et d'identification du noyau des représentations sociales. In: Guimelli C, editor. Structures et transformations des représentations sociales. Neuchâtel: Delachaux et Niestlé. 1994; p.199-232

22. Ferreira ABH. Dicionário Aurélio Eletrônico século XXI. Versão 3.0 - PC. Rio de Janeiro: Nova Fronteira/Lexikon Informática; 1999.

23. Brasil. Ministério da Saúde. Secretaria de Vigilância em Saúde. Saúde faz mobilização em massa contra a poliomielite. [on line]. [2004 Jun 11]. Disponível em: http://dtr2001.saude.gov.br/svs/imu/imu01.htm.2001b

24. Moscovici S. A representação social da psicanálise. Rio de Janeiro: Zahar Editores; 1978.

25. Flament C. Aspects périphériques des répresentations sociales. In: Guimelli C, organizador. Structures et transformations des représentations sociales. Lausanne: Delachaux et Niestlé. 1994; p. 85-115.

26. Ferreira SL. Crenças das mães em relação à vacinação. Rev Bras Enferm. 1984; 37: 109-15.

27. Quirino MD. Vacinação da criança durante o primeiro ano de vida: conhecimento das mães e ações educativas desenvolvidas pelos funcionários das Unidades Básicas de Saúde do Município de São Paulo [doutorado]. São Paulo: Escola Paulista de Medicina da Universidade Federal de São Paulo; 1998. 